\title{
Mental Health of Parents who have Children with Autism
}

\section{Sawitree Wongkittirungrueang}

Autistic Research Center, Faculty of Education, Khon Kaen University, Thailand

"Corresponding author: Sawitree Wongkittirungrueang, Professional Level, Lecturer, Autistic Research Center, Faculty of Education, Khon Kaen University, Thailand, Tel: +66994609171; E-mail: rsawit@kku.ac.th

Rec date: Dec 21, 2015; Acc date: Jun 26, 2016; Pub date: Jun 30, 2016

Copyright: (c) 2016 Wongkittirungrueang S. This is an open-access article distributed under the terms of the Creative Commons Attribution License, which permits unrestricted use, distribution, and reproduction in any medium, provided the original author and source are credited.

\begin{abstract}
Children with autism were not mental retarded children. But, they had developmental disorder, and were slow in some activities. So, they were different from mental retardation. However, autism might be occurred with mental retardation. Consequently, it was necessary to precisely discriminate the autism, and mental retardation. Because the support technique and method in some issues, were different. It might be concluded that the children with autism were children group with problem in language development, communication, social or interpersonal interaction. They had sort attention span or low concentration, hardly sit still. Some of them may have behavioral and emotional problems.
\end{abstract}

\section{Keywords: Children; Autism; Symptoms}

\section{Introduction}

Children with autism were classified into Pervasive Developmental Disorder since there was no conclusion what would be the cause of Autism due to the lack of accurate evidence to support. As a result, treating autism had to be performed based on the occurred symptoms or investigated symptoms the same as in general persons [1]. So, the first second the parents knew that their children had autism symptom. Every parent would have reaction on the feeling inevitably. Moreover, the parents had to step over the bad situation to another side in order to be able to meet "the acceptance of truth," at the end. Before passing the difficult situation, some families had to face with different problems including: physical problem, mental health problem, and social problem etc. The parents of children with autism would have high level of anxiety since the children might have various symptoms. Some symptoms were completely different such as some children with autism would have low intelligence, but some of them had high intelligence as the gifted children. Some couldn't speak or had no spoken language. But, some of them had speaking ability etc. [2]. In this article, the characteristic of children with autism, historical background of autism, psychological approach of adjustment of parents whose children had autism symptoms, technique of support when parents knew that their children were autistics, would be stated.

\section{Characteristics of Children with Autism}

Autism Spectrum Disorder has been known for almost 70 years. It was called in many names and were changed periodically including The Autistic Disorder), Autism, Autism Spectrum Disorder), Pervasive Developmental Disorders), (PDD Not Otherwise Specified and Asperger's Disorder. Recently, the academics agreed to use the words "Autism Spectrum Disorder" according to the criterion of DSM-5 which was formally used in 2013. In Thailand, it should be called "Autistic" in every sub-group since it was used for a long period of time. The other names would be diminished. Autistic was a disorder of child development with unique characteristic. The children could not develop their social and communicative skills appropriately with their ages. Their behavior, activity, and interest were repetitive as well as limited in some issues. They were not flexible. These problems were occurred since they were young. Consequently, the children had limitation in their life. The academic tried to study in details. But, they were not able to find the cause precisely. It was found that although the cause was not clearly known, it was likely to be occurred with males rather than females all over the world.

But, it was not we couldn't do anything with them since the present support and care were able to help this children group to be better very much. Specifically, when they were diagnosed and taken care adequately since they were young, and performed continuously [3].

\section{Symptoms and Diagnosis}

The Diagnostic Statistical Manual of American Psychiatrist Association, the 4th Issue, Revised Edition, 2000, (DSM-IV-TR, 2000) classified Autism in every spectrum of diagnostic group called Pervasive Developmental Disorders including 5 sub-groups as follows [4]:

The system of classification based on universal standard of World Health Organization, the 10th Issue, Revised Edition, in 2011(ICD-10, version 2010) using the same word "PDD," but it was classified into 8 sub-groups.

In 2013, the diagnosis was changed based on The Diagnostic Statistical Manual by American Psychiatrist Association, the 5th Issue, (DSM-5, 2013) called "Autistic" (Autism Spectrum Disorder) with no sub-group. The criterion was changed very much including 2 major characteristics as social communication and social interaction, and restricted, repetitive patterns of behavior, interest or activities.

The major keys as predictors for Autism in 18 year-old up children, included 4 major symptoms. If there were more than 2 symptoms being occurred, it might be "Autistic." In addition, there should be implementation to ascertain the diagnosis of symptoms as well as to provide support immediately. These symptoms were:

\section{- Lack of pretend play}

- Lack of proto declarative pointing 
- Lack of social interest

- Lack of joint attention

\section{Historical Background of Autism}

The word "Autism," was from Greek "Auto" referred to Self which meant that to withdraw themselves in their own world comparing with glass wall or mirror separating these persons from surrounding society [4].

In 1943, there was the first patient report by Doctor Leo Kanner, a psychiatrist at John Hopkins Institute in The United States of America. He reported 11 child patients with peculiar symptoms such as imitating the spoken sound, slow speaking, difficulty in communication, doing something repeatedly without changing, not being interested in the other persons, not being able to play. He followed up these children for 5 years, and found that the children were different from children with intellectual impairment. So, these children were called "Early Infantile Autism."

In 1944, Doctor Hans Asperger, an Austrian pediatrician described the children who had difficulty in society, preoccupied with doing something repeatedly and strangely. But, they were very talkative and seemed to be very intelligent. The children with these symptoms were called "Autistic Psychopathy." However, nobody conducted these studies again after the second world war. In 1981, Lorna Wing cited Autism in the meaning of Asperger similar to Kanner very much. So, the latter researchers concluded that these 2 doctors stated the same topic with different details. Recently, it was organized in the same group as "Pervasive Developmental Disorders" or "Autism Spectrum Disorder."

In 1994, Aurisric was classified in the diagnosis as "Pervasive Developmental Disorders," based on criterion of psychiatric diagnosis of American Psychiatrist Association the IV Issue (DSM-IV, 1994), and the Revised Issue 2000 (DSM-IV-TR, 2000). The diagnostic criterion of World Health Organization the 10th Issue, the Revised Issue 2011 (ICD-10, 2011), the same name has been called until now.

Since there was an increased knowledge of autism from collection of research studies all over the world. As a result, there were changes in diagnostic criterion differently from the former ones. The same name was called in every sub-group as "Autism Spectrum Disorder" as the criterion in Diagnostic Statistical Manual of American Psychiatrist Association, the 5th Issue (DSM-5) which was formally used in 2013.

\section{Psychological Principles of Adjustment for Parents of Children with Autism}

According to the study of Kubler-Ross stated the 4 prominent reactions of parents as: The stages, popularly known by the acronym DABDA, (Kübler-Ross model).

1. Denial they did not believe whether their children had disability such as autism symptom, mental retardation etc. Many families brought their children to see many persons including in Science, Buddhism, and Occultism depended on their beliefs to search for answer what their children would be.

2. Anger some persons were moody, had no reason, projected themselves or start to project each other father projected mother or mother projected the father which could affect good relationship in family as well as thinking power for developing their children to be progress further.

3. Bargaining was duration to bargain with everything. Some of them bargained with their

with or vow. Some may bargain with treatment style. Some might search for or try to find the person, technique, or process to help their children.

4. Depression some parents might feel very sad regarding to their children's symptoms. Some of them may ask themselves-Why me. Since they could not accept the truth they had to face with. They always had feeling of a deep sad until it could affect their daily life activities such as going to work, the interaction with their friends or society. Some may withdraw themselves from the others since they didn't want to contact with the others or being asked some questions about their children or they may compare their children with the others.

5. Acceptance-was the duration the family could be able to start the process for developing their children as best as they could. They were ready to fight with the occurred fate. The family power increased more and more. When the parents accepted the fact that their children had autism symptom, they would understand. Finally, they could see how to solve the problem. If they didn't accept the truth and prolonged their time, it would have bad more effect on their children. Since their children might be taken care incorrectly and inappropriately.

In Thailand, Metisa Pongsaksri study "The Changes of Family with Early Childhood Autistic Children, and Family with Adolescent Autistic, found that the Family with Early Childhood Autistic Children had changes in their family in "Moderate" level every aspect. But, the Family with Adolescent Autistic had changes in their daily life and mind in "High" level, and changes in social aspect in "Moderate" level. As a result, it affected the children's parent very much especially their mental health problem as well as anxiety and stress in their child rearing practices. Specifically, it included the impulsivity and aggression. The stress in parents of children with autism had an impact on their family; the husband-wife relationship was affected. In some families, father left his child leaving burden in taking care of their children with the mother only. Since the mother had to look after her child by herself. So, she couldn't do her occupation or earn her living. Consequently, the divorce was occurred. The parents' problems of economic, working, and occupation were occurred. Since they didn't have anybody taking care of their children or they could find the caregivers for their children but the caregivers couldn't tolerate with the children with autism. When the children's parents had chronic depression being risky for committing suicide or Suicide Thought as well as the psychiatric problem such as depression, suicide thought. Moreover, it was the vicious cycle being obstructed the supportive process, behavior modification, and child development enhancement because the parents were not able to cooperate with the medical staffs in providing support for them fully and efficiently.

Preutisak Chantratip conducted research titled "Factors predicting the Mother's Stress in taking care of children with autism," the findings found that:

1. For $49.53 \%$ of children with autism' mothers, they had stress in "Moderate" level.

2. The mental health of children with autism' mothers, severity of autism symptom, duration for caring children with autism, and 
readiness for taking care of children with autism could jointly predict the stress in providing care for children, for $40.00 \%$.

3. The mental health of children with autism' mothers, had power in predicting the stress in providing care for children with autism, in "The Highest" level. The second order consisted of the severity of autism symptom (5.9\%), duration for caring children with autism (2.8\%), and readiness for taking care of children (1.1\%) respectively. It was indicated that the mental health of children with autism' mothers, was major predictive power for stress in providing care for children with autism. Consequently, in taking care for children with autism, the team should not overlook the promotion for mental health of mothers of children with autism in aligned with the care for children further.

It could be viewed that the parents with children with autism, had high anxiety of their child rearing practice as well as child training, the expenditure affecting family, husband-wife relationship until it would cause divorce at the end. The parents' economic and occupational problems were occurred since they couldn't find the caregiver for them or they could find but the caregiver couldn't be tolerate with children with autism. Moreover, when the father or mother was chronic depressive which was very risky to commit suicide.

\section{Techniques for Support when One Knew One's Child was a Child with Autism}

In providing support for children with autism, although it couldn't help them to be free from this symptom, they could be developed nearly the same as normal persons. There were 2 major aspects to support them (Center of Curriculum Development, Ministry of Education; Sompob Reungtrakoon; Alisa Wacharasin cited in Sawitree Rooncharoen) as follows: Pharmacotherapy, recently, there was no any kind of medicine to treat autism Completely, but many kinds of medicine were useful as well as able to be used to treat some symptoms of autism, for instance, the Methylphenialate in children with behavior disorder such as doing something repeatedly without changing what they were familiar with, the psychiatric medicines were recommended such as Haloperidol Clomipramine or Fluoxetine, in Impulsive Children without concentration, the Clonidine or Imipramine would be recommended etc. Each kind of medicine would decrease the problematic behaviors of children with autism. But, it couldn't be completely well.

Behavior therapy: Children with autism had behavioral problems. Therefore, the behavior modification of problematic behavior as well as rehabilitate and develop the appropriate behaviors were necessary for them very much. The implementation had to be collaborated from every division relating to children especially their parents, caregiver, physician, psychiatrist, therapist, and teachers. All of 3 divisions had to cooperate with each other regularly and continuously.

Parents were the first teachers for children. Since they had to pay their attention, be warm with, and know how to observe their children's behavior and development in order to be information or data for treating or curing the problematic behaviors, develop appropriate behavior, and help their children to follow the advice of physician and therapist. Parents of children with autism had to have high level of patience, be strong, accept the real situation, and adjust situation in family for everyone to participate in caring the children.

Physicians referred to pediatrician, psychiatrist, psychiatric nurse, psychologist, and speech therapist. These therapists had to cooperate with parents and teachers, help to cure, provide advice, and practice in order to lower down the problematic behavior, enhance the self-help skill, and develop other skills etc.

\section{The Integrated Guidelines for Taking Care of Children with Autism}

Taking care of children with autism, it was necessary to administer team working of Multidisciplinary Team Approach including Child and Adolescent Psychiatrist, Psychologist, Child Psychiatry Nurse, Medical Scientist in Communication, Occupational Therapist, Special Education Academic, Social Worker, etc. [4].

There were many guidelines for taking care of children with autism. There were 10 major guidelines as follows: [4]

1) Family Empowerment

2) Ability Enhancement

3) Development of Intervention

4) Behavior Modification

5) Speech Therapy

6) Occupational Therapy

7) Social Skills Training

8) Educational rehabilitation

9) Vocational Rehabilitation

10) Pharmacotherapy

\section{Family empowerment}

The family played the most important role in helping children with autism. Since it was not any one's duty. It was every one's duty. Family power was the power of success. The major advices that every family member should understand were as follows:

The Autism was caused by one's brain function disability which was not precisely Known. But, it was ascertained that it was not caused by child rearing practice. Don't blame oneself that one did not provide good child rearing practice, and one's child was the child with autism.

Autism could be developed by integrated care. Don't choose only one being thought that it was the best way to take care of one's child. The child was center of treatment which needed to be planned or designed appropriately with each one.

Family was an important mechanism for providing support so that the treatment would be efficient.

\section{Ability enhancement}

According to research studies, found that there were $10 \%$ of children with autism who had special ability. These groups of children were called "Autistic Savant." In foreign countries, children's special abilities which were mostly found including: musical ability especially the piano playing. Besides, the Art Ability, Mathematical Calculation Ability, Calculation from Calendar, and Spatial Relation Skill, were also found. In Thailand, there were no sufficient statistical data.

Providing opportunity for children to play various kinds of toys as well as participate in many activities such as music, sports, art works, helping one's parents' work would enhance opportunity for children to express their ability to be seen more. 


\section{Developmental intervention}

Basic skills for learning that should be firstly practiced in order to move children from their personal world into the outside world. Eye contact, concentration, listening, and following one's order should be emphasized. The beginning duration of these skill practices, was time consuming. In addition, the changes could be slowly seen. Consequently, both of parents, an children were stressful. However, when children had these basic skills, the extension for more difficult skills wasn't difficult anymore.

Activity of Daily Living Training should be practiced simultaneously by providing the learning process in routine activities for children to be able to perform by themselves with full potentiality with the support in lowest level. In practicing, it was necessary for children to learn step by step until they could do it themselves until it was their habit to be used in their daily life. It was to help children to help themselves based on their potentiality, decrease their parents or caregivers' support Furthermore, the children would be proud of themselves when they could perform activities by themselves.

\section{Behavior modification}

The Behavior Modification Program consisted of the Applied Behavior Analysis; ABA, and the Behavioral Modification Procedure which aimed to enhance the appropriate behaviors to be continuously performed, to stop the problematic behavior, and to develop the desired new behavior.

The program being ascertained as the effective one, was the Lovaas Program by an intensive face to face training using the applied behavior analysis focusing on face to face training at home intensively and continuously, 40 hours a week, 6 months continuously. It was very productive in children being practiced when they were younger than 5 years old. It was found that the children could learn as well as improved their intelligence until they could study in the same class with normal children.

\section{Speech therapy}

The practices guidelines to help children with autism to speak appropriately with their age were as follows [3]:

Try to speak with children regarding to what they were looking at or doing in order to set the goal for looking at meaningfully.

When there was a noise occurred around children, they should be suggested to pay attention in listening regularly by imitating to speak the same as the occurred sound. While doing something for children, one should speak about what one was doing for them so that they would learn vocabularies as well as content of vocabularies, and to develop learning the meaning from real practice.

Comprehension from vocabularies should be taught before speaking. Children's speaking should be taught by using the expressions which were concrete, easily remembered, familiar with, and nearby ones. Children should be provided opportunity to utter their sound by speaking first for them. Then, time space should be provided them for uttering, and wait for them to speak. Don't speak instead of waiting them. Be good example for children by speaking clearly, and using correct words since they would imitate from person whom they talked with.
Poetry or poem or song might be used for stimulating children to speak. Because it was to help them to be interested in as well as easy for them to remember.

Some children had to be administered special techniques for stimulating their interest, and developing their readiness in language teaching and speaking by preparing the meaningful looking and listening, practicing the movement of one's lips, tongue, and sound uttering.

The persons, who played an important role in practicing and correcting children's speech, were not the experts. They were persons who were close with children. So, don't wait until the appointment to practice since it wouldn't be useful as it should be. The parents were able to stimulate their children to speak through playing as well by trying to develop situations to encourage communication such as while they were playing jigsaw, one piece of jigsaw might be hidden so that the children would ask for it, or one would bring the others' shoes for children to wear so that the children would say that "No," or asking for their own shoes etc. Moreover, the practice method being advised from the experts should be practiced regularly.

\section{Occupational therapy}

The Occupational Therapist would be the person who applied various activities to help in treating the children according to each one's condition. The delimitation of occupational therapist's work would cover the followings:

1) The teaching and training for children to perform their daily life activities by themselves, for instance, eating food, wearing clothes etc.

2) The activities to enhance one's competency in self-control of Hyperactivity, Aggression, and No eye contact children.

3) The activities stimulating one's sucking, chewing, and swallowing.

4) The activities for readiness preparation in various skills as Educational Basis, for instance, writing skill training, reading skill training etc.

5) The activities for practicing one's movement skill, stimulating one's upright neck, crawling, and walking etc.

6) The activities for increasing one' muscle strength in persons with weak muscle.

7) The activities for enhancing one's hand using for picking or catching, or doing one's daily life activities,

8) The activities for practicing one's communicative skill.

9) The activities for practicing one's social skill.

10) The stimulation for being able to adjust oneself with environment or society for living happily without being burden of family or other persons.

11) The invention for equipment or aids doe children to be able to help themselves in dressing, cleaning themselves, eating food etc.

12) The consultation for playing activities which could enhance one's development and learning in school.

\section{Social skill training}

Social skill was the major defective for children with autism. As a result, this skill had to be practiced in special. It often was emphasized 
Page 5 of 6

on the eye contact, smiling, participation, listening, continuous conversation, attention, understanding the other persons, and appropriate emotional response. It could be performed by simulation in incidence or social situations to be practiced until they were skillful, teaching to remember the dialogue patterns in situations for using directly.

Social stories developed by Gray [5]. The stories or social situations were determined to teach children by emphasizing on major social characteristics, reactions expected to be occurred from general children and children with autism, and the reasons for reactions in order to help children with autism to be able to understand the occurred situations in society, the other persons' emotion and feeling, and how to behave themselves appropriately with those situations as well as adjust themselves with society by decreasing their problematic behaviors.

\section{Educational rehabilitation}

The Educational Rehabilitation played an important role in improving one's social And communication skill, and thinking skill leading to long range benefit. The program content emphasized on readiness preparation for being truly used in children's daily life instead of training for academic skill only.

The interesting teaching program in classroom, was the TEACCH (Treatment and Education of Autistic and related Communication Handicapped Children) developed by Dr. Eric Schopler focused on systematic teaching and environmental management appropriately with children, as the major key. The classroom was developed systematically and hierarchically. In addition, the materials were organized in groups. The time schedules for activities were fixed. The precise expectation was determined. Consequently, children knew what they had to do. Teaching was performed step by step. In teaching method, the picture was emphasized rather than sound. The children were taught how to use the pictures or signs. The content covered every aspect of skills. In Thailand, the Educational Rehabilitation for children with autism, was changed and developed continuously based on National Education Act 1999, and the Revised Issue (the 2nd Issue) 2002 (The 3rd Issue) 2010, Section 10, Space 2, stated that the Educational Management for persons with physical disability, mental disability, intellectual disability, emotional disability, social and communication disability, and learning disability or persons with physical handicap or crippled or persons who couldn't help themselves or without caregiver or underprivileged persons, those persons had to be provided their right and opportunity for Basic Educational Management in special.

\section{Vocational rehabilitation}

The present approach of Vocational Rehabilitation, was changed from working in hospital or factory into real labor market or private occupation under supervision, occupational training, work providing, and systematic support in order to accomplish goal for the persons to earn revenue as well as live independently, to depend on the other persons least. So, the readiness preparation was required, for instance, the punctuality, the adjustment with super ordinate and colleagues, work security, which included both of basic skill, and vocational skill $[6]$.

\section{Pharmacotherapy}

The pharmacotherapy did not aim to cure to be absolutely well from autism. But, it was used for treating some symptoms being occurred. It was not necessary for all children to be treated by medicine. After taking medicine, they did not have to take it for the rest of their life. The physician had to adjust the dose of medicine or stop giving it when the target symptom got better [7].

Recently, it was not found which kind of medicine would be used for treating the social and communication disorder as major problem. For the medicines being used, found that it could be useful for decreasing the Hyperactivity, Impulsivity, Inattention, Aggression, Obsessive Preoccupation. There were various kinds of medicine including: Neuroleptics, SSRI (Selective Serotonin Reuptake Inhibitor), and Psych stimulant etc.

\section{Complementary and alternative medicine}

In addition to the major guidelines using for curing as the above, in the present, the Complementary medicine as well as various alternatives to be selected for using in aligned with major guidelines to be appropriate with the problem as well as obtained response from each child. The important thing should be understood, was the Complementary medicine as well as various alternatives being used for curing based on major guidelines to be more efficient. It should not be used only one thing or have to choose only one thing to be effective. The supplementary medicine and alternatives consisted of:

1) Art Therapy

2) Music Therapy

3) Drama Therapy

4) Animal Therapy

5) Acupuncture

6) HEG; Hemoencephalogram

It could be seen that the children with autism had disorder development, and were slow in some aspects. However, the autistic symptom might be occurred with Mental Retardation. Consequently, when the parents knew that their children were autistics, the first thing they had to do was to make up their mind to accept the truth. Then, they should collaborate in searching for guidelines in taking care of children with autism continuously in an integrative form through the support from family, the enhancement in children's ability, the development of intervention, the behavior modification, the occupational therapy, the speech therapy, the occupational rehabilitation, the pharmacotherapy, and the supplementary medicine and alternatives including: the Art Therapy, Music Therapy, Drama Therapy, Acupuncture and HEG, Hemo-encephalogram. These things had to start from family as well as related persons to collaborate in developing the children with autism regularly until they could help themselves and be able to live in society without being burden with themselves and the society [8].

\section{References}

1. Limsila P (1997) Diagnosis for Autism. Ch Sangngam Printing, Samoot Prakan. Pomgsakson, Metita. The Changes of Family with Middle Childhood Autistic and Family with Adolescent Autistic. Faculty of Associated Medical Science, Chinghai University. 
Citation: Wongkittirungrueang S (2016) Mental Health of Parents who have Children with Autism. J Health Edu Res Dev 4: 176. doi: 10.4172/2380-5439.1000176

Page 6 of 6

2. Rooncharoen S (1996) Technique for Caring and Supporting the Children with Autism. Journal of Academic Service Center 1: 9-16.

3. Siriratrakha T (2010) Guideline for Autism integration.

4. Siriratrakha $\mathrm{T}$ (2010) History of autism spectrum disorder.

5. Chantratit P (2009) Factors Predicting the Stress in Caring of Mothers of Children with Autism. Graduate School, Chiengmai University.

6. Sirairatreka $\mathrm{T}$ (2007) The Assessment and Diagnosis of Disability in Autism Group. In Handbook for Assessment and Diagnosis of Disability in Autism Group based on The Act for Promotion and Development of Disability's Quality of Life.

7. Daranee S (2010) Bangkok: The Agriculture Cooperative Association of Thailand Limited, pp: 46-48.

8. Toongmepon P (2005) Social Support: Readiness for Caring and Stress of Mothers of Children with Autism. Chinghai: Chinghai University. 